http://jmscr.igmpublication.org/home/ ISSN (e)-2347-176x ISSN (p) 2455-0450 crossref DOI: https://dx.doi.org/10.18535/jmscr/v8i2.75

\title{
Peri-operative Management of Huge Goitre with Compromised Airway
}

Authors

\author{
Dr Kartik Syal ${ }^{1}$, Dr Ankita Chandel ${ }^{2}$, Dr Manjit Singh Kanwar ${ }^{3}$ \\ ${ }^{1}$ Associate Professor Department of Anaesthesia IGMC, Shimla \\ ${ }^{2,3}$ Ex registrar, Department of Anaesthesia IGMC, Shimla \\ Corresponding Author \\ Dr Ankita Chandel
}

\begin{abstract}
Goitre has always remained a known risk factor for difficult airway. The never ending challenges are being faced by an anaesthesiologist all through the pre-operative, intra-operative and post-operative period. We report the anaesthetic management of world's second largest and India's largest goitre with tracheal narrowing and deviation which further required re-exploration for bleeding from the surgical site. Though awake fiberoptic intubation remains procedure of choice in this scenario but carries failure rate. Also availability of flexible fiberoscope is still limited, mandating use of alternate techniques which sometimes provide better alternative to failed fiberoptic intubation.
\end{abstract}

\section{Case Report}

A 60-year-old male patient not known to have any medical illness, presented with history of neck swelling noted $40 \mathrm{yrs}$ ago. The swelling was increasing gradually in size and was associated with dyspnea especially with neck flexion. There was no history of dysphagia, pain, change of voice or any history suggestive of hyper or hypothyroidism. The patient was fully investigated and the diagnosis of huge colloid goitre was established for which he was planned for subtotal thyroidectomy.

His body weight was $48 \mathrm{~kg}$, heart rate 80 beats/min and blood pressure 130/80 $\mathrm{mmHg}$. Neck examination showed a huge swelling, about $20 \times 25 \mathrm{~cm}$, moving with swallowing, firm to soft in consistency, smooth surface, non tender, with overlying skin showing areas of necrosis (Fig 1). Indirect laryngoscopy revealed normal vocal cord mobility. Airway examination showed adequate mouth opening, modified Mallampati's class (MPC) II, mild limitation of neck extension and severely restricted neck flexion.

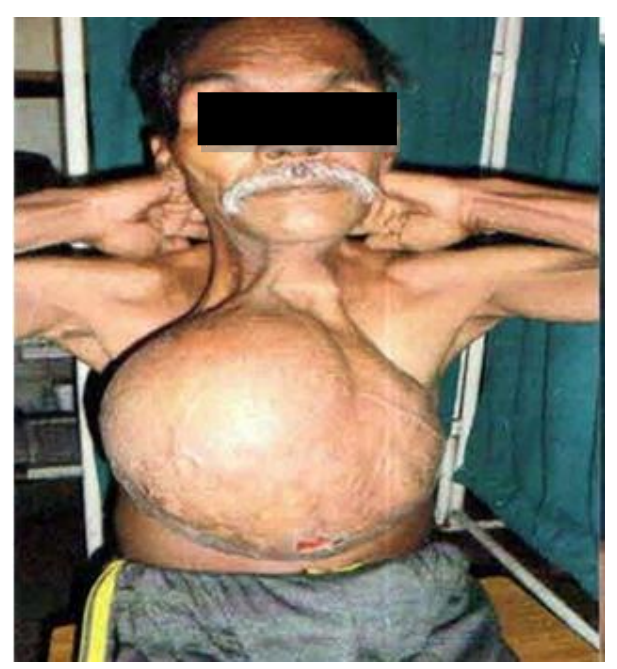

Figure 1: Huge goiter 20x $25 \mathrm{~cm}$ 


\section{JMSCR VoI||08||Issue||02||Page 431-435||February}

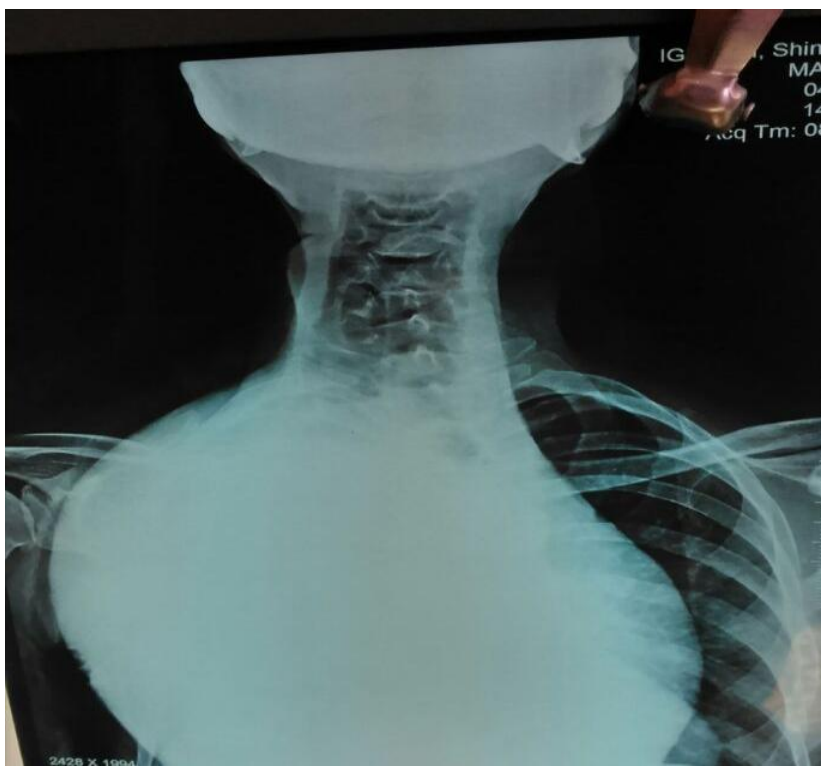

Figure 2: X-ray neck (AP view) shows goiter

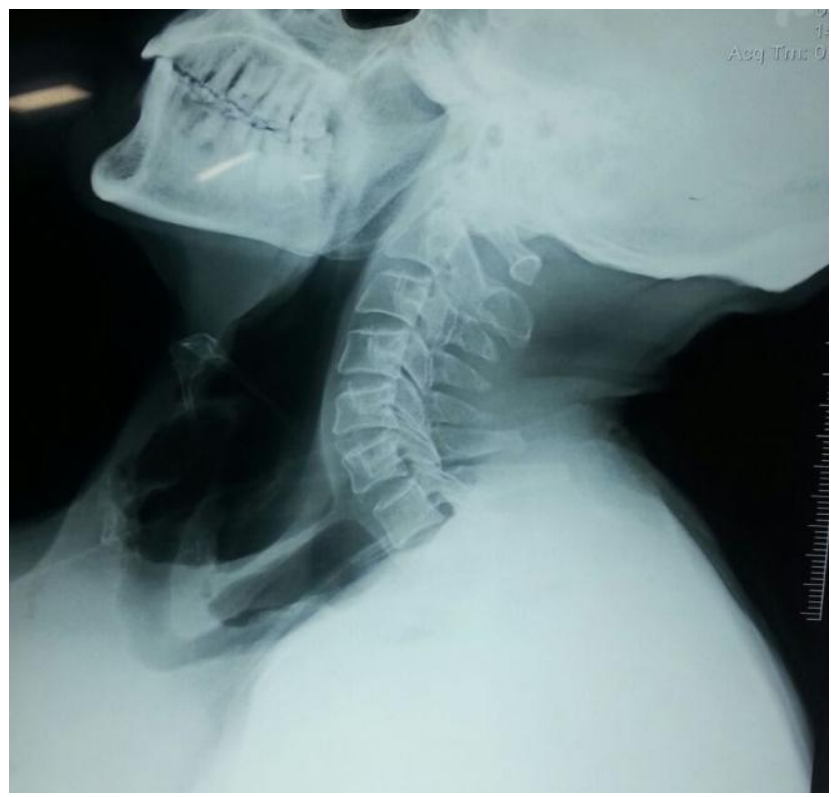

Figure 3: X-ray neck (Lateral view)

Cardiovascular system examination revealed ejection systolic murmur (attributed to anemia, $\mathrm{Hb}$ being $8 \mathrm{gm}$ ). Chest examination showed bilateral good air entry with no added sounds.

Laboratory investigations including thyroid function tests were within normal ranges. An ultrasound was done which was suggestive of colloid goiter. Radiological examination of the swelling revealed attenuation of airway with lateral displacement of the trachea to the right on anteroposterior view and lateral view was unremarkable as tracheal shadow merged into mixed solid- cystic tumour shadow of equal $x$ ray lucency (Fig 2,3). CT scan showed 20x25 cm huge mass deviating and narrowing the trachea to some extent, though there was no tracheal erosion or infiltration. It also showed the tumour to be bending the carotid arteries (Fig 4). Fine needle biopsy showed colloid goiter. The patient was scheduled to undergo subtotal thyroidectomy under general anesthesia.

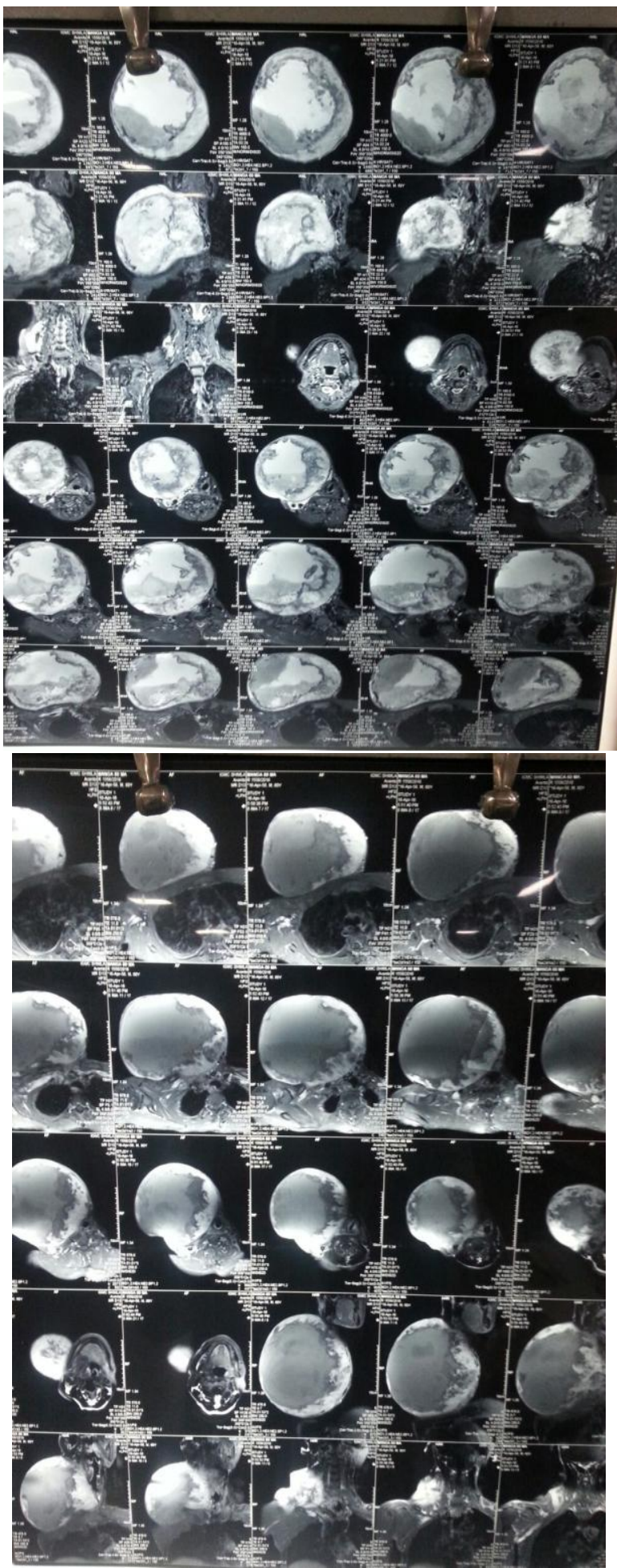

Figure 4: CT scan 
Premedication was achieved with oral alprazolam $0.25 \mathrm{mg}$ one night before surgery and 2 hours prior to surgery. Difficult airway management cart (included ventilating bougie,) was kept ready, and the patient shifted on the OT table. Standard monitors (namely, ECG, Pulse Oximeter, NIBP) were attached and the baseline vitals recorded. A $16 \mathrm{G}$ i.v line was established in left forearm.

An arterial line was established in left radial artery and a double lumen central line was inserted in left femoral vein because of distorted anatomy and huge mass near neck veins. Patient was explained the entire procedure and pre oxygenation was done with $100 \%$ oxygen for 3 minutes. The entire mass was held and lifted from outside by assistant anaesthetist to prevent collapse of airway.

Inj. Glycopyrrolate $0.2 \mathrm{mg}$ i.v. was administered. Slow titrated dose of fentanyl $100 \mu \mathrm{g}$ and propofol $100 \mathrm{mg}$ were given and ventilation was checked. As the ventilation was possible so $50 \mathrm{mg}$ of succinylcholine and the trachea was intubated using $7.5 \mathrm{~mm}$ armoured endotracheal tube (ETT) with direct laryngoscopy. ETT was guided to the right bronchus and then moved proximally (to the point where bilateral equal air entry was heard) so that it was placed beyond the swelling to prevent any chance of obstruction to flow during surgery. Patient was then given thyroid surgical position which ensured ETT to be far from carina to save from its stimulation. Injection atracurium $20 \mathrm{mg}$ iv was given, all lines and tube was secured, and surgery commenced. Anaesthesia was maintained with $\mathrm{N} 2 \mathrm{O}: \mathrm{O} 2$ :: $70: 30$ and isoflurane $0.6-1.2 \%$. Analgesia was supplemented with inj. diclofenac $75 \mathrm{mg}$ iv and paracetamol $1 \mathrm{gm}$ iv infusion. Inj dexamethasone $8 \mathrm{mg}$ iv was given to decrease airway edema. Intraoperatively episodes of bradycardias and ventricular irregularities occurred specially while dissecting near the carotids for the surgeon was immediately asked to stop the surgical manipulation and Inj atropine 0.6 $\mathrm{mg}$ was given, and surgery was allowed on restoration of sinus rhythm. Inj. Magnesium sulphate $1 \mathrm{gm}$ by slow iv infusion was further given for cardiac stability.
After surgery vocal cord movements were checked and patient was shifted intubated to Intensive care unit for spontaneous recovery considering high chances of airway oedema and even respiratory distress due to tracheomalacia owing to long standing duration of huge goitre and accompanied airway compression.

After 1 hour, patient's incision site begun to swell with oozing from the suture line. Patient was immediately shifted to operation theatre. Surgical site was re-sutured and haemostasis was achieved under mild sedation with analgesia provided by Inj. Midazolam 1mg iv and Inj. Fentanyl $75 \mu \mathrm{g}$ iv along with local anaesthesia infiltration.

Patient was given Inj dexamethasone $8 \mathrm{mg}$ iv at night and nebulisation with Adrenaline was done 8 hourly. Patient was kept on Pressure support overnight under midazolam and morphine infusion. Next morning, patient was planned for exubation. Cuff leak test was performed which was positive and the endotracheal tube was gradually withdrawn over tube exchanger, in view of reintubation, in case if needed. Patient maintained well and was discharged without any medical problems.

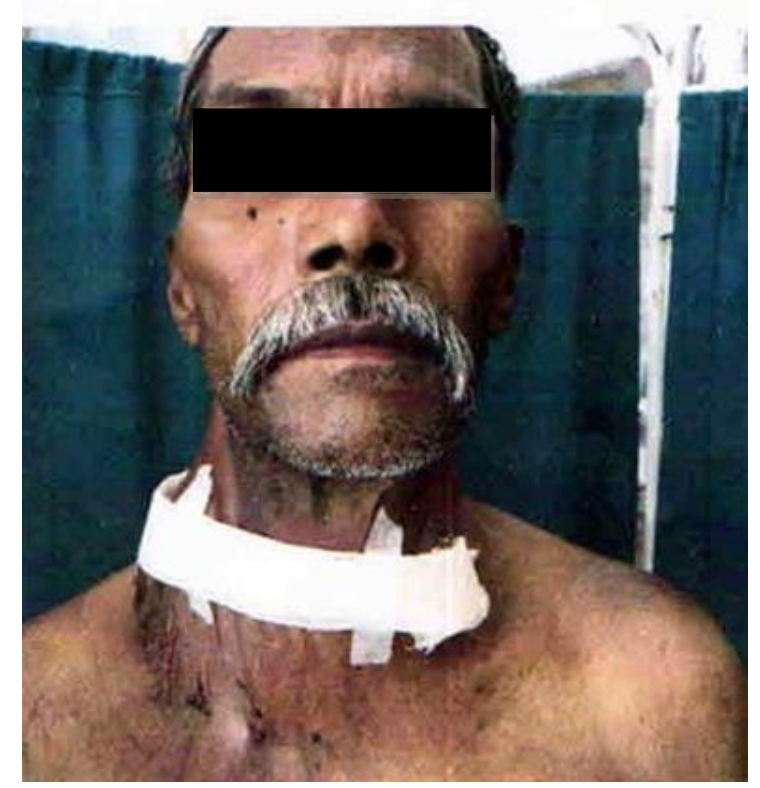

Figure 5: Patient at the postoperative period.

\section{Discussion}

Airway crisis is an ever-present risk of general anaesthesia in goiter with compromised airway. 
Upper airway obstruction due to thyroid gland has been reported up to be present in $31 \%$ and difficulty in intubation has been reported to be around $11 \%{ }^{1}$ Present case represents one of the largest goitre operated upon in India till date. Airway management in cases of airway obstruction has been described with direct laryngoscopy, rigid bronchoscopy, fiberoptic bronchoscopy, LMA, jet ventilation and femorofemoral bypass. The success or failure of the airway management largely depends on proper evaluation and planning preoperatively.

In our case, X-ray soft tissue neck lateral view showed deviation of trachea. Further evaluation was done with CT to see exact airway anatomy. These investigations showed narrowing and deviation of trachea but without any erosion or infiltration.

The major concerns thus revolved around securing the airway and also planning for safe extubation. Though major complications in airway management are rare but are amongst the most life-threatening in medicine. ${ }^{2,3}$

Awake fibreoptic intubation (AFOI) is regarded as the gold standard technique for difficult airway management but its availability is still limited and the technique also has failure rates ${ }^{4}$ Woodall and colleagues have reported $11 \%$ failure rate of awake fiber-optic intubation apart from the other complications like epistaxis (nasal approach), laryngotracheal trauma, laryngospasm. ${ }^{5}$ But most importantly, the use of topical local anaesthesia in AFOI sometimes serves to reduce dynamic air flow with loss of muscle tone and normal reflex responses, which may even precipitate airway collapse in already compromised airway. ${ }^{6,7}$

In our case we planned to hold the mass from outside to prevent airway collapse and relaxant was administered only after checking for ventilation while difficult airway cart was kept by side. The patient was intubated safely and it was ensured that the distal end of the tube lies beyond the mass by first going for endobronchial intubation then gradually withdrawing the tube to the point where bilateral air entry is just heard.
Another concern was the compression of carotid arteries by the mass, dissection around carotid sinus might have led to the exaggerated response of the carotid sinus baroreceptor in the form of bradyarryhthmias described as carotid sinus hypersenstivity. The reported incidence as per Kim et al.is $28 \%$ in elderly patients, and $10 \%$ in young patients. ${ }^{8}$ In our case tight monitoring of the patient helped us to readily identify the bradyarrythmias and timely intervention helped to restore sinus rhythm. The direct effect of magnesium on myocardium along with blocking of catecholamine receptors, inhibiton of release of catecholamines from adrenal medulla, further ensured myocardial stability.

Further, long standing thyroid swelling with tracheal compression alerted us to have high degree of suspicion for tracheomalacia, which was first described by Czyhlarz in 1897, and remains a heterogeneous condition with no universally accepted definition and stratification. ${ }^{9}$ Although definitive criteria are lacking, a cut-off of a 50\% reduction in tracheal lumen on $\mathrm{CT}$ is usually considered a prerequisite for diagnosis. However, in patients with extrinsic compression such as those due to goitre, tracheomalacia may theoretically only become apparent following removal of the compressive agent. Consequently, tracheomalacia may present unheralded as an emergency after thyroidectomy. Goiter of at least 5 years duration, giant size and associated tracheal narrowing have been described as significant factors contributing to tracheomalacia ${ }^{10}$ and these all were present in our patient. However, for the intraoperative diagnosis of tracheomalacia many criteria have been described in literature including a soft and floppy trachea on palpation by the surgeon at the end of thyroidectomy, obstruction to spontaneous respiration during gradual withdrawal of the ETT after thyroidectomy, difficulty in negotiating the suction catheter beyond the ETT after gradual withdrawal and absence of peritubal leak on deflation of ETT cuff. $^{11}$ It has been suggested that leaving the endotracheal tube in place for 24-48 $\mathrm{h}$ 
postoperatively serves as a splint before extubation in a controlled setting thus minimising the risk of tracheomalacia ${ }^{12}$ We therefore planned to extubate the patient after $24 \mathrm{hrs,}$, and peritubal leak around the endotracheal tube reassured safe extubation.

Apart from this, close monitoring in post operative period also helped us to promptly identify the bleed from surgical site which was managed by prompt and timely intervention.

\section{Conclusion}

In conclusion, thyroid enlargement represents an independent risk factor for difficult direct laryngoscopy and difficult tracheal intubation. Preoperative airway assessment can predict patients with possible difficult airway. Proper planning and discussing the problems with the patient and surgeon along with meticulous post operative monitoring can ensure safe outcome.

\section{Bibliography}

1. Amathieu R, Smail N, Catineau J, et al. Difficult intubation in thyroid surgery: myth or reality. Anesth Analg 2006; 103:965-8.

2. Cook TM, Scott S, Mihai. Litigation following airway and respiratory-related anaesthetic morbidity and mortality: an analysis of claims against the NHS in England 1995-2007. Anaesthesia 2010;65:556-63.

3. Cook TM, Woodall N, Frerk C. Major complications of airway management in the UK: results of the 4th National Audit Project of the Royal College of Anaesthetists and the Difficult Airway Society. Part 1 Anaesthesia. Br J Anaesth 2011;106:617-31.

4. Ali Dabbagh et al. A rapidly enlarging neck mass. The role of sitting position In Fiberopticbronchoscopy. AnesthAnalg 2008;107:1627-9

5. N. M. Woodall, R. J. Harwood and G. L. Barker Complications of awake fibreoptic intubation without sedation in 200 healthy anaesthetists attending a training course British Journal of Anaesthesia 100 (6): 850-5 (2008).

6. Claydon PJ, Cressey D. Complete airway obstruction during awake fibreoptic intubation. Anaesthesia 1997;52:1120-1.

7. Ho AMH, Chung DC, Karmakar MK, Gomersall CD, Peng Z, Tay BA. Dynamic airflow limitation after topical anaesthesia of the upper airway. Anaesth Intensive Care 2006;34:211-5.

8. Kim TI, Lim HJ, Chang SH, Kim NS. Intraoperative carotid sinus hypersensitivity and postoperative complication of radical neck dissection retrospective study. Korean J Crit Care Med. 1998;13:49-54.

9. Czyhlarz E. Ueber ein pulsiondivertikel der trachea mit bemerkungen uber das verhalten der elastichen fasern an normalen tracheen und bronchein [in German]. Zentralbl Allg Pathol 1897; 18:721-8.

10. Tripathi M. Goiter and Airway Control. World J Endoc Surg 2010;2(1):9-16.

11. Mayilvaganan S, Agarwal A. Management of post-Thyroidectomy Tracheomalacia. World J Endoc Surg 2014;6(2):96-8.

12. Singh B, Lucente FE, Shaha AR. Substernal goiter: a clinical review. Am J Otolaryngol 1994;15:409. 